\title{
Technological Progress, Spatial Competition and Industrial Location: Estimation and Predictions of Cement Industry in Northwest China
}

\author{
Fei Wang ${ }^{*}$, Qiliang Mao \\ ${ }^{1}$ School of Public Policy and Management, Tsinghua University, Beijing, China \\ ${ }^{2}$ School of Urban Economics and Public Administration, Capital University of Economics and Business, \\ Beijing, China \\ Email: "more1987@163.com, chris13@yeah.net
}

Received 18 July 2016; accepted 14 August 2016; published 17 August 2016

Copyright (C) 2016 by authors and Scientific Research Publishing Inc.

This work is licensed under the Creative Commons Attribution International License (CC BY). http://creativecommons.org/licenses/by/4.0/

(c) (i) Open Access

\section{Abstract}

This study estimates a theoretical multi-region industrial location model by adopting real statistics to investigate the intuition of shaping spatial pattern of economic activities in a case of cement industry in Northwest China. Based on the estimation of key parameters, we simulate the impact of technological progress on variation of location. We find that, given trade cost, with technological progress, operating cost decreases, it is profitable for firms to expand sale range. In long term, technological progress would induce server spatial competition and promote further spatial concentration of industry. Original areas with larger market and fine industrial base are still main agglomerations, while original peripheral areas are further to a downward trend, and parts of original areas located next to hot pot areas have become peripheries. Our study on influence of technological progress on industrial location confirms the importance of investigation on intuition of spatial pattern of economic activities. Technological progress is essentially achievement of sustainable development. However, neglecting substantial spatial competition induced by technology improvement turns against spatial allocation of resources. Hence, optimal location of industries is one of important factors to ensure sustainable development.

\section{Keywords}

Spatial Competition, Industrial Location, Technological Progress, Market Access, Computable Spatial Economic Model

\footnotetext{
${ }^{*}$ Corresponding author.
}

How to cite this paper: Wang, F. and Mao, Q.L. (2016) Technological Progress, Spatial Competition and Industrial Location: Estimation and Predictions of Cement Industry in Northwest China. Modern Economy, 7, 984-995. 


\section{Introduction}

Industrial location is the projection of economic activities on the territory. It is the common fact that economic activities unevenly distribute across space. Both New Economic Geography and Traditional Trade Theory confirm that industrial special pattern is closely related to its own characteristics. Technology level is one of the key industrial characteristics measuring the mode of production. With technology progress, one given industry substantially updates its own features. It is interesting as well as meaningful to penetrate the impact of technology progress on evolution of industrial location, and furthermore helpful to understand the endogenous mechanism of industrial spatial pattern.

Location theories argue that industrial spatial distribution depends on the interaction of industries with different characteristics and locations with various features, and the pattern is a temporal equilibrium under severe spatial competition of economic activities. Predicted by NEG, the interplay between trade costs, increasing returns to scale and market size lies at the heart of the pattern of regional disparities [1]. In the mechanism of spatial competition, the balance of the forces induces concentration of production due to scale economy and forces cause dispersion due to trade cost that shapes distribution of the economic activities. In the framework of spatial economics, there are usually two forces that determine equilibrium: one is the advantage to access of market, which is the agglomeration force that induces economic activities to concentrate in a given region; the other one is market competition which is the dispersion force that induces the spread of economic activities in a densely agglomerated region of firms, and severe completion limits the profitability and prevents from further concentration. In long term, it is the tug of war of agglomeration and dispersion forces that determines the equilibrium of economic geography. The industrial locations, which are stable, come out to have a reasonable transport radius, and make the firm sizes fit market potential. By concerning about technology progress on evolution of industrial location, Tabuchi et al. (2014) [2] argue that rising labor productivity may foster the agglomeration of activities; when labor is heterogeneous, the number of workers residing in the more productive region increases by decreasing order of productive efficiency when labor productivity rises.

Recently, there are lots of studies about industrial characteristics and industrial location. Brulhart and Torstensson (1996) [3] find that the industries with relatively obviously scale economy are mostly spatially concentrated. Amiti (1999) [4] also finds agglomerated industries have the feature of intensive intermediate inputs. Midelfart-Knarvik et al. (2000) [5] analyzed the spatial pattern of industries within EU, then they argued uneven distribution of industries across countries or interior of a country was closely related to industrial characteristics such as labor intensity, R\&D investments, etc. There are differences for industries with different features of forward-backward linkages or scale economy trend to location in developed countries or in backward countries. Vogiatzoglou (2006) [6] analyzed industrial specialization and geographic concentration patterns within the NAFTA, and found that manufacturing was increasingly relocating to Mexico, which came at the expense of the US. In addition, labor-intensive and low-technology activities appear to be the most spatially concentrated industries, exhibiting a strong increasing trend to relocate to Mexico. The researches on China reach similar conclusions. He and Xie (2006) [7] pointed out the spatial distribution of industries characterized by industrial differential inherent features when specialization pattern had been clear across provinces of China since 1990s. The industries indicate differential spatial pattern in terms of export-oriented, material-oriented, consumptionoriented, highly profitability, and high taxation.

Concerning research methods, spatial economists usually apply general equilibrium theory to industrial location. It has been the main framework to analyze impact factors of industrial location. But equilibrium condition of spatial economic model consists of nonlinear equations, which are hardly to reach analytic solutions. And in consequence solution of models rely on numerical simulation. This restricts spatial economic models to be applied in the real world. Combes and Lafourcade (2011) [8] made an attempt to a computable spatial equilibrium simulation; they employed real statistics to estimate parameters of theoretical model, then used estimated parameters to simulate landscape of economy. This method, to a certain degree, overcomes the defects that core-periphery model excessively rely on numerical simulation and improve utility of spatial economic model. The exercises in computable spatial equilibrium under imperfect competition are rooted in studies by Smith and Venables (1988) [9], Haaland and Norman (1992) [10], and Gasiorek et al. (1992) [11]. Gasiorek and Venables (1997) [12] produced the first study that was close to economic geography: it focused on the impact that improvements in infrastructures had on the spatial concentration of activities.

The main contribution of our paper is to provide further intuition on the balance between agglomeration and dispersion forces in high-dimension economic geography models with strategic interactions among firms. We 
use our estimated parameters to simulate the distribution of economic activities, market fragmentation, and the determinants of firm location (prices, costs, mark-ups, marginal profits, demand and total profits).

\section{The Economic Geography Model}

Both economists and geographers generally believe market with larger scale more likely to be a location of production [1]. As a sort of friction force, transportation cost is closely related to economic geography, which is a main force affect industrial location and spatial expand. It implies that proximity to market is one of the factors determine a location. It was taken up by Weber (1962) [13] to analyze a firm's optimal location. Weber assumes that the firm aims at minimizing total transport costs, which are defined by the sum of weighted distances to several markets, each weight expressing the importance of the corresponding market to the firm. This amounts to assuming that a firm seeks a location that gives it the best access to several markets, which have different sizes and relative positions. However, Weber's framework ignores the spatial competition, he assumes fixed price for both sellers and buyers, and there is no substantial competitors. This assumption seems appropriate in the context of single firm, but it is not right as considering several locations of firms in the same sector. Palander (1936) [14] recognizes the importance of spatial competition between firms, he commits to analyze firms in different location delimitate market. However, his work is based on given location. It is still unknown how location settled. It is more reliable to predict industrial location if combine agglomeration force (access to market) and dispersion force (firm competition). Hotelling (1929) [15] developed a location model involved spatial competition, which implies industrial location is endogenous.

In next paragraphs, we add technology variable to Combes and Lafourcade (2011) [8]'s general equilibrium model of industrial location, which aims to evaluate impact of technological progress on change of location by adopting data of cement industry in Northwest China.

\subsection{Theoretical Model}

Production function. Within industry $s, n_{j}^{s}$ single-plant firms operate in region $j$ where they produce the same homogenous good. Technology differs across industries but not across regions. The production of a representative firm operating in industry s and region $j, y_{j}^{s}$, is

$$
\begin{gathered}
y_{j}^{s}=A\left(l_{j}^{s}\right)^{\alpha^{s}} \prod_{z}\left(K_{j}^{z}\right)^{\beta^{z}}, \alpha^{s}+\sum_{z} \beta^{z}=1 \\
C_{j}^{s}=l_{j}^{s} w^{s}+\sum_{z} K_{j}^{z} p_{j}^{z}+f_{j}^{s}
\end{gathered}
$$

where $l_{j}^{s}$ is the number of employees and $K_{j}^{z}$ the quantity of good $z$ used as an intermediate input. $\alpha^{s}$ and $\beta^{z}$ are constant parameters. Moreover, we assume that firms incur fixed production costs, $f_{j}^{s}$, which are industry- and region-specific. In order to focus on technological progress affect the location of firms, we improve the production function by employing total factor productivity $A$ which refers technological level. The larger $A$ is, the more goods produced for given $l$ and $K$. Under technology (1) and (2), marginal cost and average cost are respectively given by

$$
\begin{gathered}
M C_{j}^{s}=\left(\frac{1}{A}\right) \frac{\left(w^{s}\right)^{\alpha^{s}} \prod_{z}\left(p_{j}^{z}\right)^{\beta^{2}}}{\left(\alpha^{s}\right)^{\alpha^{s}} \prod_{z}\left(\beta^{z}\right)^{\beta^{z}}} \\
A C_{j}^{s}=\left(\frac{1}{A}\right) \frac{\left(w^{s}\right)^{\alpha^{s}} \prod_{z}\left(p_{j}^{z}\right)^{\beta^{z}}}{\left(\alpha^{s}\right)^{\alpha^{s}} \prod_{z}\left(\beta^{z}\right)^{\beta^{2}}}+\frac{f_{j}^{s}}{y_{j}^{s}}
\end{gathered}
$$

where $w^{s}$ is the wage in industry s, that assumes not vary across regions to simplify our analysis. $p_{j}^{z}$ denote the price in intermediate input $z$ and region $j$. Through cost function, we can carry out our interests. The marginal cost is constant if wages and intermediate input prices are fixed. The cost function not only indicates to what extent marginal cost change as production factors but make clear that marginal cost declines in the circumstance of technological progress.

For the representative firm operating in industry $s$ and region $j$, labor and intermediate demands are therefore: 


$$
l_{j}^{s}=\left(\frac{1}{A}\right) \alpha^{s} \frac{c_{j}^{s} y_{j}^{s}}{w^{s}}, \quad K_{j}^{z}=\left(\frac{1}{A}\right) \beta^{z} \frac{c_{j}^{s} y_{j}^{s}}{p_{j}^{z}}, \quad \forall z
$$

Consumer demand and good-market equilibrium

Let $Q_{j}^{s}$ denote the final consumption of good $s$ in region $j$, and $\gamma^{s}$ the share of good s in consumers' expenditure, with $\sum_{s} \gamma^{s}=1$. Under the assumption that consumers share the same Cobb-Douglas preferences across regions, final demand in region $j$ is

$$
\begin{gathered}
Q_{j}^{s}=\frac{\gamma^{s} R_{j}}{p_{j}^{s}} \\
R_{j}=\sum_{z} w^{z} n_{j}^{z} l_{j}^{z}+\bar{R}_{j}
\end{gathered}
$$

where $R_{j}$ is consumer income in region $j$, given by the sum of the local (endogenous) wage bill, and other (exogenous) income, $\bar{R}_{j}$.

The total demand for good $s$ in region $j, D_{j}^{s}$, is the sum of final and intermediate consumption, $R_{j}^{s}$ is the total expenditure devoted to industry $s$ in region $j$

$$
D_{j}^{s}=Q_{j}^{s}+\sum_{z} n_{j}^{z} k_{j}^{z}=\frac{R_{j}^{s}}{p_{j}^{s}}
$$

We further assume that markets are segmented. $y_{i j}^{s}$ the firm's exports from region $I$ to region $j$ in industry s. The clearing condition in market $j$ reduces to

$$
\sum_{i} n_{i}^{s} y_{i j}^{s}=\frac{R_{j}^{s}}{p_{j}^{s}}
$$

Firms’ strategies under Cournot competition

Due to markets segmentation, we use $t_{j i}^{s}$ as the additive trade cost of delivering one unit of good s from region $j$ to region $i$. The profits of a representative firm of industry $s$ located in region $j$ can be written as

$$
\pi_{j}^{s}=\sum_{i}\left(p_{i}^{s}-c_{j}^{s}-t_{j i}^{s}\right) y_{j i}^{s}-f_{j}^{s}
$$

We assume that firms behave as Cournot-Nash oligopolists. Eachfirm chooses to maximize its profit. The first order conditions are given by

$$
\frac{\partial \pi_{j}^{s}}{\partial y_{j i}^{s}}=p_{i}^{s}-c_{j}^{s}-t_{j i}^{s}-\frac{p_{i}^{s} y_{j i}^{s}}{D_{i}^{s}}=0, \forall i
$$

In the short-run equilibrium, the number of firms is exogenous. Let $N^{s}=\sum_{j} n_{j}^{s}$ be the total number of competitors in industry s. More explicit expressions of non-corner equilibrium price and quantities result from Equations ((9) and (11)):

$$
\begin{array}{r}
p_{j}^{s}=\frac{\sum_{i} n_{i}^{s} t_{j i}^{s}+\sum_{i} n_{i}^{s} c_{i}^{s}}{N^{s}-1} \\
y_{j i}^{s}=\frac{p_{i}^{s}-c_{j}^{s}-t_{j i}^{s}}{\left(p_{i}^{s}\right)^{2}} R_{i}^{s}, \forall i
\end{array}
$$

Spatial equilibrium mechanisms and influence of technological progress

Economic activities are determined by interaction between agglomeration and dispersion. Competition tends to disperse firms across space. Due to strategic interactions, the equilibrium price from Equation (12) falls with the total number of competitors in each industry (Ns) and with proximity to these competitors: the closer are the other producers in industry s, the smaller is $\sum_{i} n_{i}^{s} t_{j i}^{s}$.With the same regional demands, technological level and price of inputs across regions, the further away the competitors, the greater the firm's production, marginal profit, and total profit at the Cournot equilibrium(market clear).Firms therefore have incentives to locate in areas 
where competition is weaker. By way of contrast, competition also indirectly creates agglomeration incentives through its impact on local demand and costs. Due to home-market effect, total production is higher where there are more firms, even were all markets to be of equal size. Because expenditure is endogenous, both intermediate and final local demands are higher in equilibrium in areas where competition is fiercer, which has a further positive feedback on the home market effect. These demand linkages increase the production of individual local firms relative to others, and consequently their profits. Furthermore, intermediate input prices are lower in regions where competition is tougher, yielding a further endogenous agglomeration incentive: production costs are lower in regions with more firms, also increasing short-run profits. Hence, both demand and cost linkages give firms incentives to locate in, or near to, larger areas. In two region case, the endogenous final demand effect is likely to offset competition, producing greater short-run profits in regions where firms are more numerous. Firm entry is thus more pronounced in these locations. An asymmetric long-run equilibrium may pertain, with one region having a greater concentration of firms. The classic core-periphery model (Krugman, 1991) [16] effectively describes this very spatial equilibrium mechanism. It is more difficult to arrive at similar predictions in the multi-region context, that is, difficult to prove analytically. For instance, as trade costs fall, mediumly-competitive regions may lose firms to regions where competition is less fierce, while attracting firms from regions where it is stronger. Moreover, we have also made the model richer by considering technological progress and inputs structure. Alternatively, we carry out an econometric estimation by adopting real statistics to get "reasonable" parameter values to stimulate industrial location.

Even so, the influence of technological progress on industrial location to some extent still can be correctly forecasted in common-sense. Given the other conditions, technological progress leads to reduce marginal cost as well as home price of goods. The price of exports from region $j$ to region $i$ maybe decrease, and the negative profit before $\left(p_{i}^{s}-c_{j}^{s}-t_{i j}^{s}<0\right)$ would be very likely to turn to positive $\left(p_{i}^{s}-c_{j}^{s}-t_{i j}^{s}>0\right)$. Unless trade cost is so high as to protect local firms, demands of region's goods in region $i$ will be very large, and the balance of two regions' industrial scale will be adjusted. Home-market effect is undoubtedly important determinates of evolution of industrial location. The firms in large market, in the circumstance of technological progress, average cost will decrease, which will improve the profitability, and more important, it is profitable to reach the further away markets with same trade cost. Therefore, the firms in larger markets can gain more profits than the ones in smaller markets, firm entry is thus more pronounced in these former locations. It can be predicted that evolution of industrial location affected by technological progress has a close relationship with regional market size, nevertheless, specific influence rely on stimulation in below.

\subsection{Empirical Model and Estimable Specification}

Data on value-added, capital, price, or intermediate input costs do not exist in West-north China at the disaggregated spatial scale (county specific) considered here. However, data on employment and number of firms are available. Our baseline estimation therefore builds on firm labor demand. We derive a specification of area- industry employment per firm $l_{j}^{s}$ from the equilibrium conditions, which allows us to estimate the model parameters that are missing in West-north China data. Production of area j equals local consumption plus supply to other areas.

$$
y_{j}^{s}=\sum_{i} y_{i j}^{s}
$$

Equations ((2), (3) and (14)), yield

$$
l_{j}^{s}=\left(\frac{1}{A}\right) \frac{\left(\alpha^{s}\right)^{1-\alpha^{s}} \prod_{z}\left(p_{j}^{z}\right)^{\beta^{z}}}{\left(w^{s}\right)^{1-\alpha^{s}} \prod_{z}\left(\beta^{z}\right)^{\beta^{2}}} \sum_{i} y_{i j}^{s}
$$

We assume that trade costs per unit exported, $t_{i j}^{s}$, are proportional to distance between each pair of counties. Denoting by $\delta^{s}$ the coefficient of proportionality for industry s, we assume that:

$$
t_{i j}^{s}=\delta^{s} t_{i j}
$$

By adopting specification of Combes and Lafourcade (2011), we build up aempirical model of industrial location:

$$
l_{j}^{s}=\sigma^{s}+\delta^{s} Z_{j}^{s}+\sum_{s^{\prime} \neq s} \delta^{s^{\prime}} Z_{j}^{s^{\prime} s}+\varepsilon_{j}^{s}
$$


where $\sigma^{s}$ is an industry-specific intercept and $\varepsilon_{j}^{s}$ a random component reflecting the measurement errors. The $Z_{j}^{s}$ and $Z_{j}^{s^{\prime} s}$ variables are complicated functions of the observed variables, in particular the number of firms and employment by industry-area, and transport costs between all areas. As this specification is linear in the unknown parameter $\delta^{s}$, we estimate it by OLS. As long as these estimates are consistent and robust to standard econometric checks, they can be plugged back into the equilibrium equations in order to simulate the predicted spatial patterns from the model.

We adjust the estimated specification of Equation (17) by considering the features of cement industry, in which intermediate inputs are mainly the energy of electricity and natural resources such as limestone and mine, besides rare products of other industries included. So a multi-region model with intermediate inputs from own industry only is derived as Equation (18). Equations ((19)-(23)) are the expression of variables.

$$
\begin{gathered}
l_{j}^{s}=\sigma^{s}+\delta^{s} Z_{j}^{s}+\varepsilon_{j}^{s} \\
\sigma^{s}=\frac{N^{s}-1}{N^{s} w^{s}} \sum_{i} R_{i}^{s} \\
Z_{j}^{s}=G^{s} \sum_{i} R_{i}^{s}\left[E^{s}\left(D^{s}-\left(1-\alpha^{s}\right) D^{s}\right)-t_{i j}\right] \\
G^{s}=\frac{\alpha^{s} p^{s} A}{\left(\alpha^{s}\right)^{\alpha^{s}} \prod_{z}\left(\beta^{z}\right)^{\beta^{z}}\left(w^{s}\right)^{1-\alpha^{s}}\left(p^{s}\right)^{2}} \\
E^{s}=\left(\frac{1}{A}\right) \frac{2 p^{s}\left(w^{s}\right)^{\alpha^{s}}-p^{s}\left(\alpha^{s}\right)^{\alpha^{s}} \prod_{z}\left(\beta^{z}\right)^{\beta^{z}}}{\left(\alpha^{s}\right)^{\alpha^{s}} \prod_{z}\left(\beta^{z}\right)^{\beta^{z}}} \\
\sum_{j} n_{j}^{s} t_{i j}^{s} \\
D^{s} p^{s}\left(N^{s}-1\right)
\end{gathered}
$$

In this case, we have $\alpha^{s}<1$, while $\beta^{z}=1-\alpha^{s}>0, t_{i j}$ refers to the distance between two counties measured by public road mileage, $R_{i}^{s}$ means cement consumption in county $i$, which has to be approximately measured by investment of fixed assets. On one hand, the county specific data of cement consumption is unavailable, on the hand, the cement consumption significantly correlate to each county's investment of fixed assets.

\section{Data and Estimation}

\subsection{Data}

For the number of firms and employment, we use the Annual Survey of Industrial Firms (ASIF) dataset for 2010 conducted by National Bureau of Statistics (NBS) in China. This dataset provides exhaustive information on the universe of Chinese firms with turnovers more than 5 million per year. In addition, it provides detailed geographical and industrial coverage, as it can be disaggregated into up to counties at the 3-digit industrial level. We derive the social fixed investment and wages by quoting Statistical Yearbook of China's regional economic 2011. With respet to technology and preference parameters, we investigated cement firms in Pingliang, Gansu province. We use highway mileage to indicate distance between pair of counties, which is gained through China's electronic map of last edition.

\subsection{Descriptive Industrial Location and Technological Progress}

Compared to other regions (East China, North China, Northeast China, Middle China, and Southeast China), aggregated economy is relatively smaller which induce less demand of cement, but the average price is higher, it just confirm the argument that the weaker competition is, the higher price will be.

The spatial pattern of cement industry in Northwest China exhibits two evident features: first, most of firms concentrate in south of Shaanxi, east of Gansu, areas along Yellow river of Ningxia and Inner Mongolia, parts of 
Xinjiang, and east of Inner Mongolia, where population and economic activities densely located; second, cement industries mainly locate city-intensive zones and their surrounding areas, where economic activities highly agglomerate, demand for cement is relatively large. Briefly analyzed, location of cement industry significantly relates to market size. Through further analysis of annual social fixed investment, scale of cement demand and supply closely correlate to local fixed investment (Figure $1 \&$ Figure 2).

\subsection{Evaluation of Technological Progress of Cement}

We evaluate technological progress of cement industry based on investigation of cement firms of Pingliang, Gansu Province, where locate two large corporations, Hailuo and Qilianshan, the former is representative of China's cement industry, which represents the highest technological level in his domain; the latter was representative firms of local Northwest China. Qilianshan's technological level lagged behind Hailuo, however, had to improve operating technology since Hailuo's entry. Hence, investigation on the cement industry of this area provides us decent materials before and after technological progress, which helps us to evaluate performance of

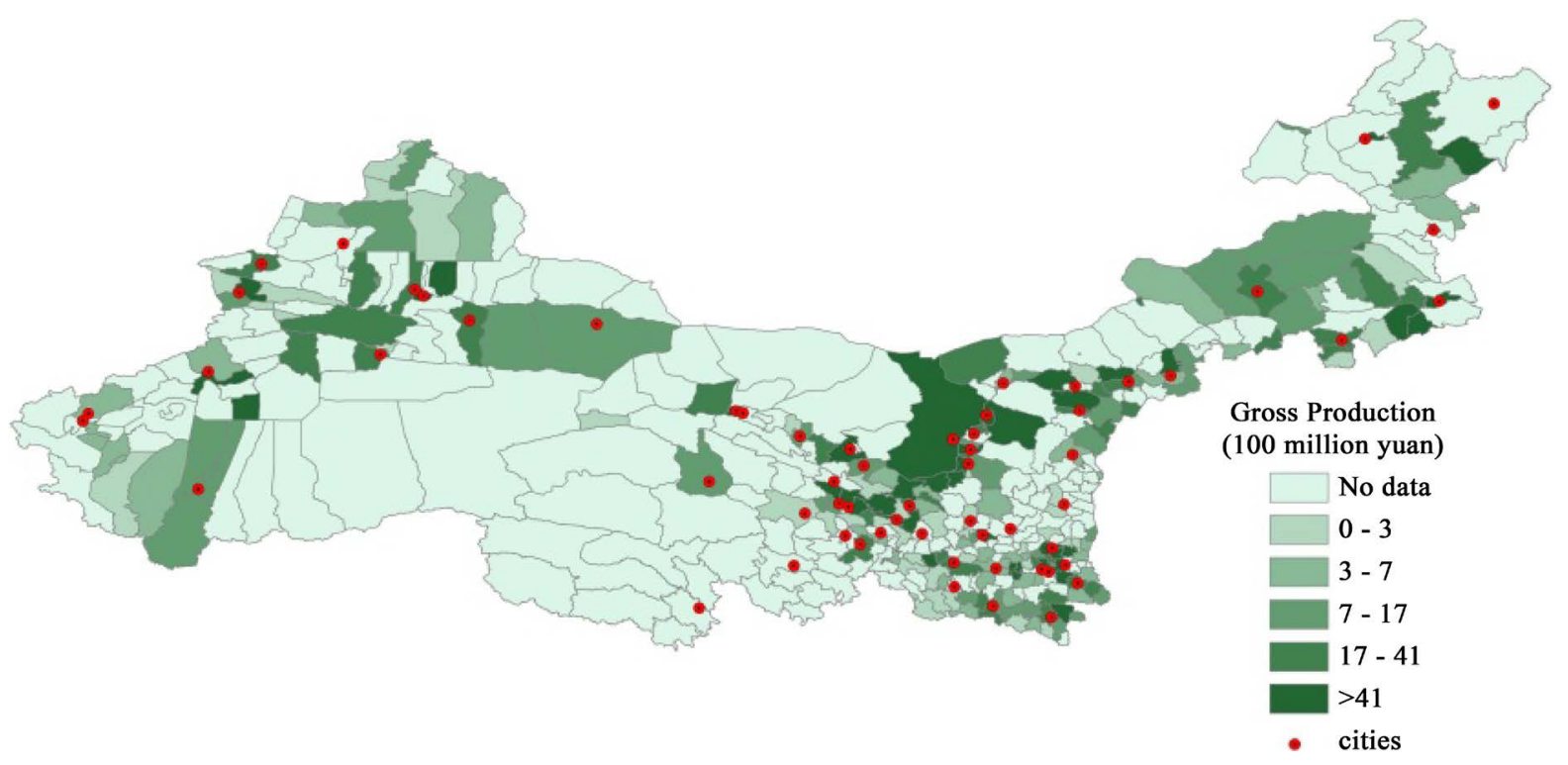

Figure 1. Spatial distribution of cement industry in Northwest China (2010).

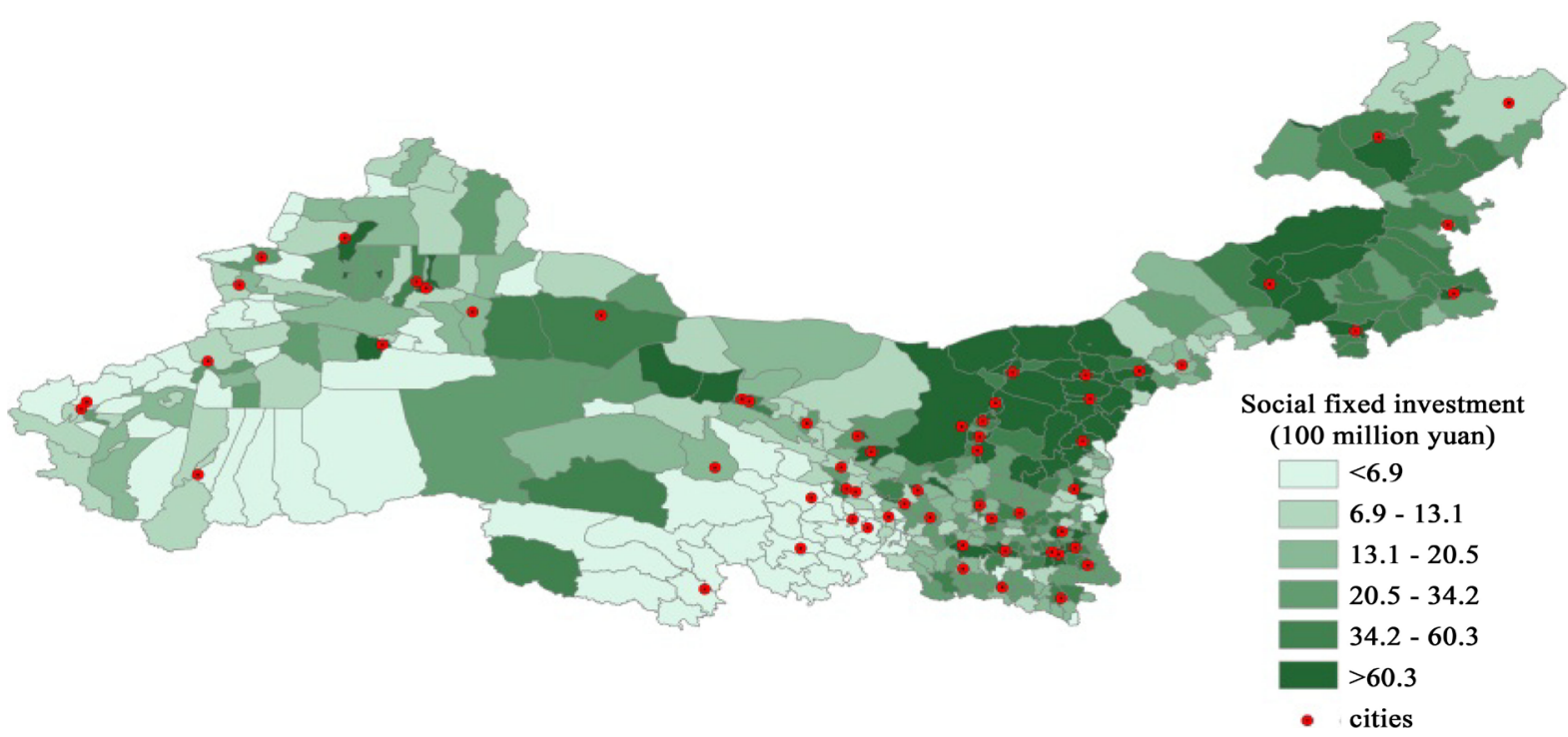

Figure 2. Spatial distribution of annual social fixed investment in Northwest China (2006-2010). 
technological progress for cement industry. Technological progress of cement industry mainly includes improvement of efficiency of resources utilization and changing structure of inputs. Recycling economy is key feature of technological progress. On one hand, firms reuse the waste generated by other industries and constructions to ease environmental deterioration; on the other hand, they utilize of heat from process of production to generate electricity to reduce energy demand. According to Kharel and Charmondusit (2008) [17]'s approach about evaluation of eco-efficiency of production, by improvement of technology, energy eco-efficiency, material eco-efficiency and waste eco-efficiency respectively increased by $3.71 \%, 58.73 \%$ and $0.8 \%$. In order to evaluate technological progress, we take the logarithm of Equation (1) to get model of production function (Equation (24)), and attribute residual aside from variation of inputs to technological progress, then estimate the function by OLS. In the function, $y_{j}^{s}$ refers to firm's gross product, $l_{j}^{s}$ refers to employment, $K_{j}^{1}, K_{j}^{2}, K_{j}^{3}$ respectively denotes limestone, energy and waste, $\mu$ measures impact of technological progress (Table 1).

\subsection{Baseline Estimation}

We estimate the model (18) and (24) using OLS in 2009. The estimated A is 11.2329 and 12.3457 respectively which indicates significant technological progress in cement industry. Concerning on the economic geography model, it is 0.2331 before technological progress and 0.2054 after that, both of them are significant in $5 \%$ level. To be consistent with the model, the estimated $\delta^{s}$ should be positive, the condition that holds before and after technological progress. The estimation means trade cost is the main force shaping spatial pattern of cement industry, and furthermore, decline of estimated coefficient is consistent with implication of model: with the same transport condition, trade cost will have less impact on industry location if average cost of production decrease. Since it is so, the estimate coefficients could be applied to predict spatial pattern of cement location in the following text (Table 2 \& Table 3).

\section{Simulated Location under Technological Progress}

\subsection{Location Incentives}

The operating profit per firm is given by Equation (10). Under the assumption that fixed costs are the same across areas, it measures the incentive to create a new plant in the area. Figure 3 and Figure 4 shows that indi-

Table 1. Variation of eco-efficiency of cement industry.

\begin{tabular}{|c|c|c|c|}
\hline & 2008 & 2010 & Improvement of Eco-Efficiency (2008-2010) \\
\hline Cement Production (10,000 t) & 105.09 & 87.42 & \multirow{3}{*}{$3.71 \%$} \\
\hline Energy $(10,000$ t standard coal) & 10.15 & 8.14 & \\
\hline Energy Eco-Efficiency (t cement grog/t standard coal) & 8.01 & 8.31 & \\
\hline Limestone $(10,000 \mathrm{t})$ & 97.86 & 51.26 & \multirow{2}{*}{$58.73 \%$} \\
\hline Material Eco-Efficiency (t cement/t limetone) & 0.83 & 1.32 & \\
\hline Usage of waste $(10,000 \mathrm{t})$ & 50.38 & 41.94 & \multirow{2}{*}{$0.8 \%$} \\
\hline Waste Eco-Efficiency (t cement/t waste) & 2.09 & 2.08 & \\
\hline
\end{tabular}

Note: Energy only include coal, reduction of standard coal derived from monthly report of Qilianshan Cement Co.; data of 2010 is only from January to October.

Table 2. OLS estimation for production function.

\begin{tabular}{ccc}
\hline & Before & After \\
\hline A & $11.2329^{* * *}$ & $12.3457^{* * *}$ \\
L & $0.1193^{* *}$ & $0.1072^{* *}$ \\
S & $0.7055^{* * *}$ & $0.6436^{* * *}$ \\
E & $0.0959^{* *}$ & $0.0969^{* *}$ \\
W & $0.1123^{*}$ & $0.1239^{* *}$ \\
Number of OBS & 120 & 120 \\
Adj R-squared & 0.98 & 0.97 \\
\hline
\end{tabular}

Nore: ${ }^{* * *}$ Significant at the $1 \%$ level. ${ }^{* *}$ Significant at the $5 \%$ level. ${ }^{*}$ Significant at the $10 \%$ level. 
Table 3. OLS estimation for economic geography model.

\begin{tabular}{ccc}
\hline & Before & After \\
\hline$\delta^{s}$ estimates & 0.2331 & 0.2054 \\
Std. Err. & 0.1073 & 0.0946 \\
$\mathrm{P}>|\mathrm{t}|$ & 0.031 & 0.030 \\
Number of OBS & 414 & 414 \\
Adj R-squared & 0.113 & 0.115 \\
\hline
\end{tabular}

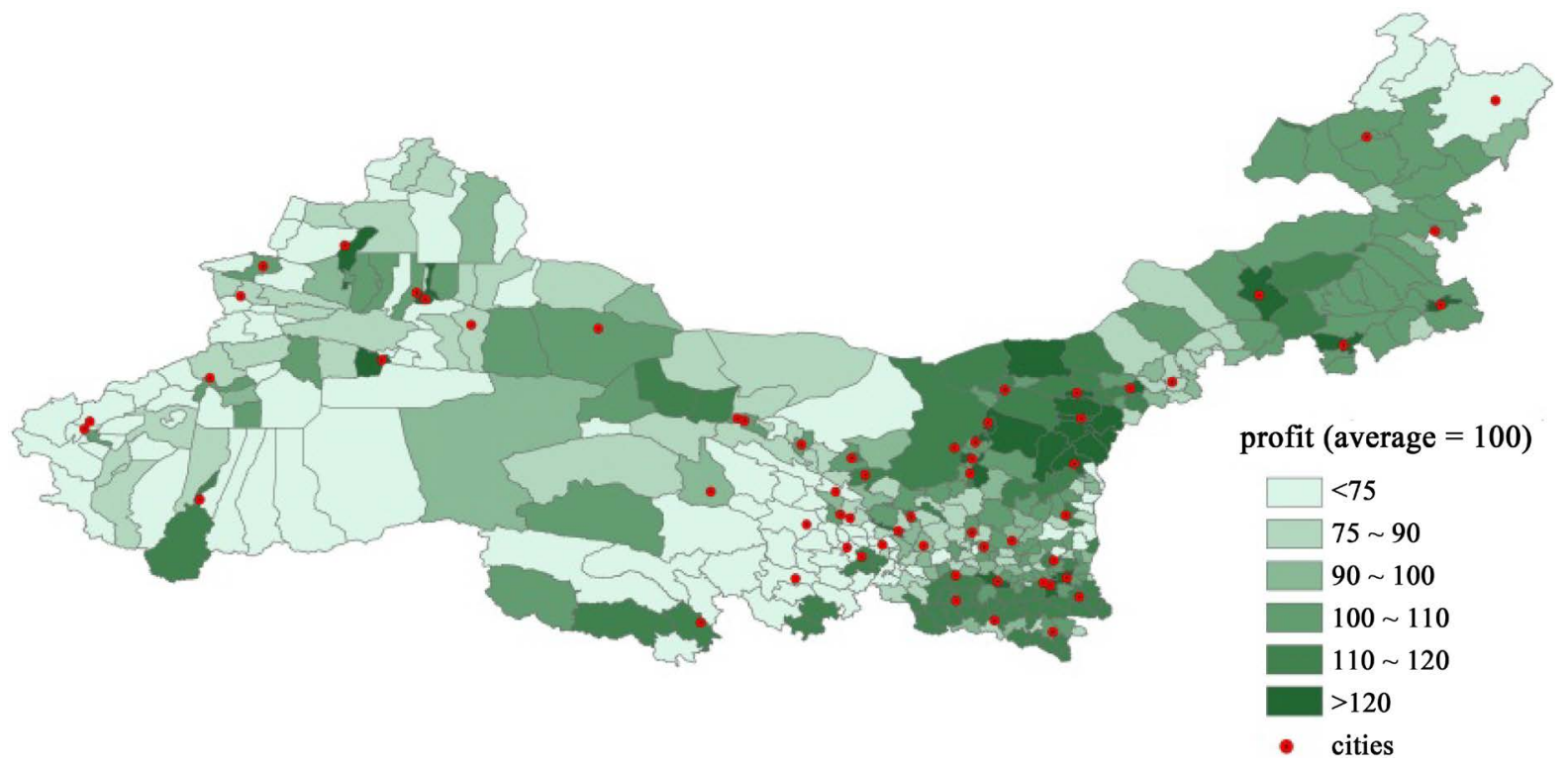

Figure 3. Marginal profit before technological progress.

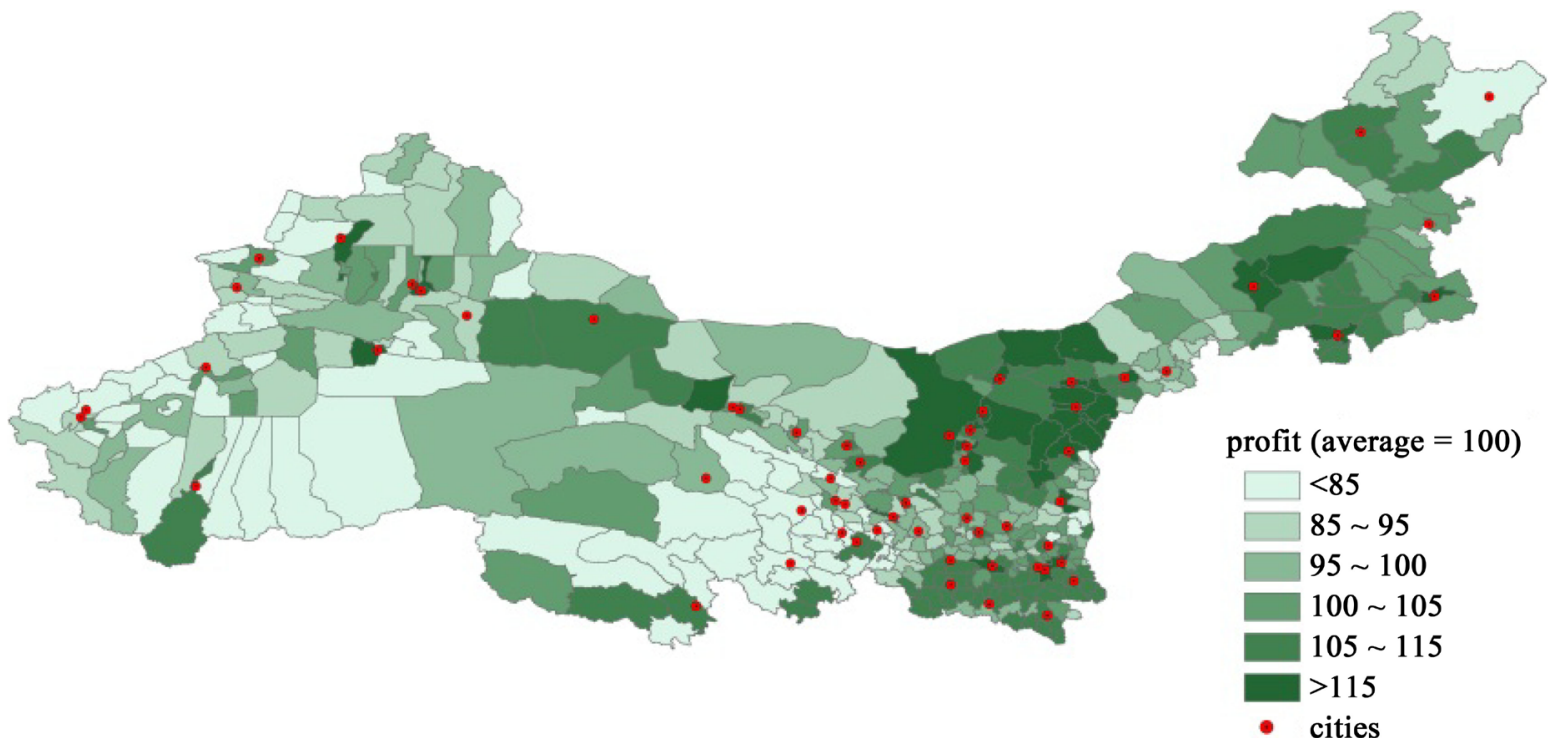

Figure 4. Marginal profit after technological progress.

vidual operating profits exhibit a clear pattern, with a negative gradient from the core to the periphery. Similar to spatial pattern of industrial scale, in the regions with cities densely located such as south of Shaanxi, east of Gansu, areas along Yellow river of Ningxia and Inner Mongolia, and parts of Xinjiang, operating profits is relatively higher than others, it indicates cement firms prefer to locate in those regions. Comparing Figure 3 and 
Figure 4, the change of operating profits before and after technological progress has been clearly showed. After technological progress, areas with high profits has been concentrated in more narrowed regions, especially urban areas in south of Shaanxi, east of Gansu and areas long Yellow river. This change implies that with progress of technology, firms are more incentive to be located in larger market and industrial base.

\subsection{Location Variation}

To further investigate the change of cement industry location with reference to production size, we evaluate the variation of hot pot. Practically, we respectively calculate local Moran's I (Getis-Ord Gi*) before and after technological progress, then adopt GIS technique to achieve in visualization, the whole region are divided into four categories in descending order of $\mathrm{Gi}^{*}$ statistic — hot pot, sub-hot pot, sub-cold pot, and cold pot (Figure 5 and Figure 6). Comparing Figure 5 and Figure 6, we can figure out shift of hot pot, meanwhile, the variation of location. Generally, before and after technological progress, distribution of cement industry is consistent with spatial pattern of profits. In terms of geographical pattern of hot pot, it is evident that cement industry mainly agglomerate in south of Shaanxi, east of Gansu, areas along Yellow river of Ningxia and Inner Mongolia, parts of Xinjiang and east of Inner Mongolia is sub-hot pot regions. In context of technological progress, the variation of location is similar to that of operating profits. Cement industry firms have been concentrated in more narrowed regions, original areas with larger market and fine industrial base still are main agglomerations,

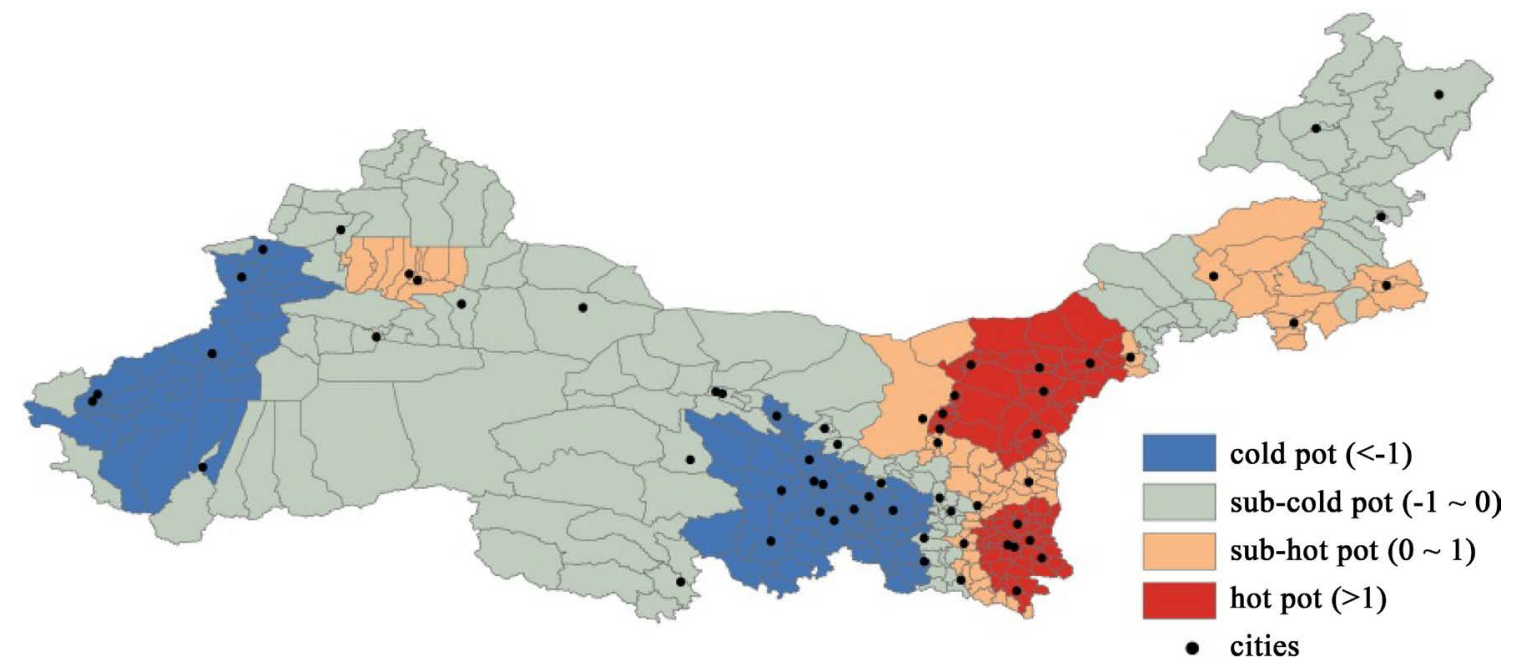

Figure 5. Hot pot of cement industry before technological progress.

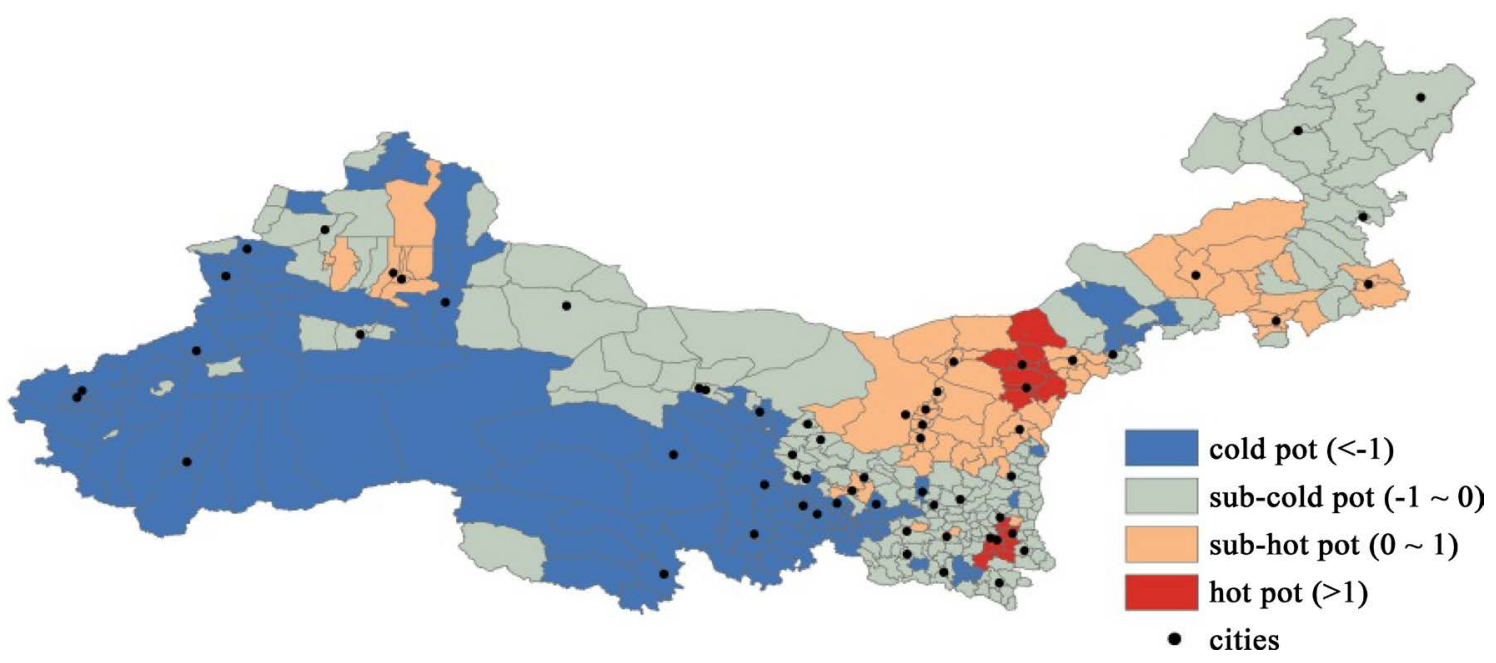

Figure 6. Hot pot of cement industry after technological progress. 
while, original peripheral areas are further me marginalized, parts of original areas located next to hot pot areas have become peripheries. From the variation of production scale, most of areas experienced decline of production to varying degree, nevertheless, central cities in west of region exhibit obvious increment.

The impact of technological progress on distribution of industry closely relates to market size. Figure 7 indicates the relation between variation of production size before and after technological progress and social fixed investment, and Figure 8 exhibits the relation between variation of production size and change of market size. Both of them imply the important effect of market size on industrial location, that is, the larger the region's home market size or its neighboring market size is, the higher possibility cement industry locate.

\section{Conclusions}

This paper estimates the theoretical economic geography model by adopting real statistics. Based on the estimation of key parameters, we simulate the impact of technological progress on location of cement industry in Northwest China. A multi-regions industrial location model is built to describe the intuition of shaping spatial pattern of economic activities. We find that with technological progress, operating cost of firms decreases, given trade cost, it is profitable for firms to expand sale range. In long term, technological progress would induce server spatial competition and promote further spatial concentration of industry. This prediction is proven in our

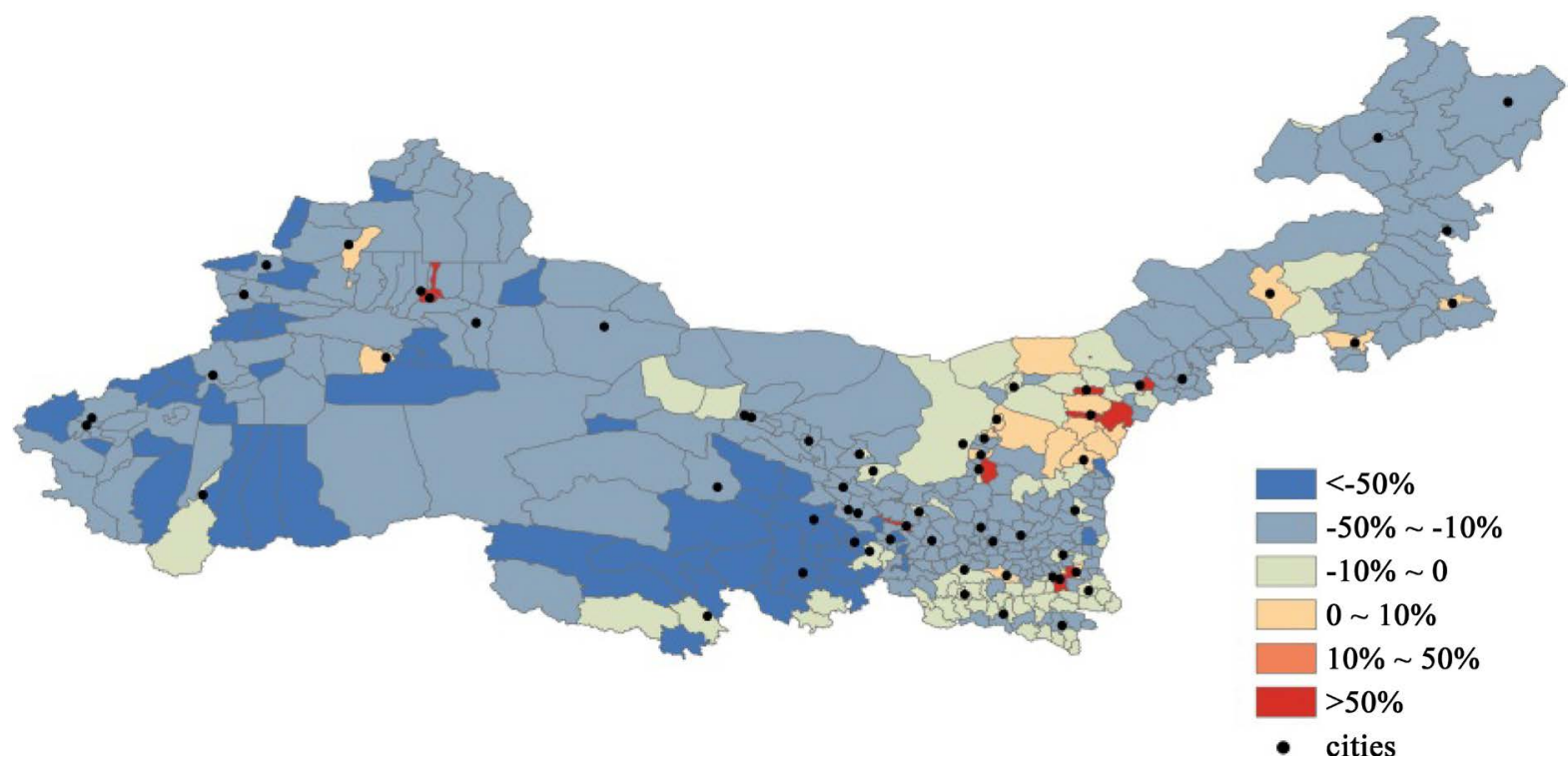

Figure 7. Change of Spatial distribution of cement product after technological progress.

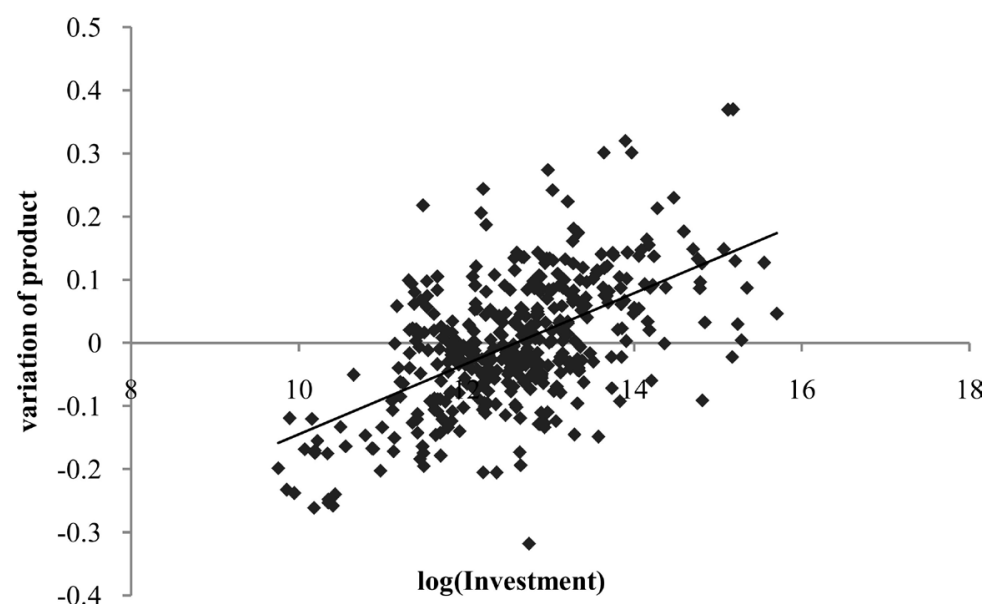

Figure 8. Correlation between variation of product and fixed investment of counties. 
case study of cement industry in Northwest China.

Our study on influence of technological progress on industrial location confirms the importance of investigation on intuition of spatial pattern of economic activities. In the case of cement industry in Northwest China, technological progress is the essentially achievement of sustainable development. However, neglecting substantial spatial competition induced by technology improvement turns against spatial allocation of resources. As industrial location is projection of economic activities on geographic space, optimal location of industries is one of important factors to ensure sustainable development.

Our approach has the attractive feature of being easy to replicate for other industries. Nevertheless, we cannot overlook the disadvantages. The real world is more complicated than we assumed in this paper, market potential is only one of the factors that influence the location, and there are lots of other determinants. It is insufficient in this paper to consider solo factors. Besides, assumption of homogeneous areas is simplification of the real word which doesn't favor more accurate estimations and simulations. Further research should focus on improvement of theoretical model which would involve more real variables precisely capture the different essence of various regions.

\section{References}

[1] Combes, P.-P., Mayer, T. and Thisse, J.F. (2008) Economic Geography: The Integration of Regions and Nations. Princeton University Press, Princeton.

[2] Tabuchi, T., Thisse, J.F. and Zhu, X. (2014) Technological Progress and Economic Geography. CEPR Discussion Papers.

[3] Brülhart, M. and Torstensson, J. (1996) Regional Integration, Scale Economies and Industry Location in the European Union. Social Science Electronic Publishing, 142, 102-10.

[4] Amiti, M. (1999) Specialization Patterns in Europe. Review of World Economics, 135, 573-593. http://dx.doi.org/10.1007/bf02707385

[5] Knarvik, K.H.M., Overman, H.G., Venables, A.J. and Redding, S.J. (2000) The Location of European Industry. Economic Papers, 1-76.

[6] Vogiatzoglou, K. (2006) Agglomeration or Dispersion? Industrial Specialization and Geographic Concentration in NAFTA. Journal of International Economic Studies, 20, 89-102.

[7] He, C. and Xie, X. (2006) Geographical Concentration and Provincial Specialization of Chinese Manufacturing Industries. Acta Geographica Sinica, 61, 21-222.

[8] Combes, P.-P. and Lafourcade, M. (2011) Competition, Market Access and Economic Geography: Structural Estimation and Predictions for France. Regional Science and Urban Economics, 6, 508-524. http://dx.doi.org/10.1016/j.regsciurbeco.2011.03.012

[9] Smith, A. and Venables, A.J. (1988) Completing the Internal Market in the European Community, Some Industry Simulations. European Economic Review, 32, 1501-1525. http://dx.doi.org/10.1016/0014-2921(88)90113-4

[10] Haaland, J. and Norman, V. (1992) Global Production Effects of European Integration. In: Winters, L., Ed., Trade Flows and Trade Policies, Cambridge University Press, Cambridge, 67-88.

[11] Gasiorek, M., Smith, A. and Venables, A.J. (1992) Trade and Welfare, a General Equilibrium Model. In: Winters, L., Ed., Trade Flows and Trade Policies, Cambridge University Press, Cambridge, 35-63.

[12] Gasiorek, M. and Venables, A.J. (1997) Evaluating Regional Infrastructure: A Computable Equilibrium Approach. "Modelling Report” by the European Institute and the London School of Economics.

[13] Weber, A. (1962) Theory of the Location of Industries. Chicago.

[14] Palander, T. (1936) Instability in Competition between Two Sellers. In Papers Presented at the Research Conference on Economics and Statistics Held by the Cowles Commission at Colorado College, Colorado College Publications, General Series No. 208.

[15] Hotelling, H. (1929) Stability in Competition. The Economic Journal, 39, 41-57. http://dx.doi.org/10.2307/2224214

[16] Krugman, P. (1991) Increasing Returns and Economic Geography. The Journal of Political Economy, 99, 483-499. http://dx.doi.org/10.1086/261763

[17] Kharel, G.P. and Charmondusit, K. (2008) Eco-Efficiency Evaluation of Iron Rod Industry in Nepal. Journal of Cleaner Production, 16, 1379-1387. http://dx.doi.org/10.1016/j.jclepro.2007.07.004 


\section{Submit or recommend next manuscript to SCIRP and we will provide best service for you:}

Accepting pre-submission inquiries through Email, Facebook, LinkedIn, Twitter, etc.

A wide selection of journals (inclusive of 9 subjects, more than 200 journals)

Providing 24-hour high-quality service

User-friendly online submission system

Fair and swift peer-review system

Efficient typesetting and proofreading procedure

Display of the result of downloads and visits, as well as the number of cited articles

Maximum dissemination of your research work

Submit your manuscript at: http://papersubmission.scirp.org/ 